\title{
COVID-19 6 months after hospital discharge: pulmonary function impairment and its heterogeneity
}

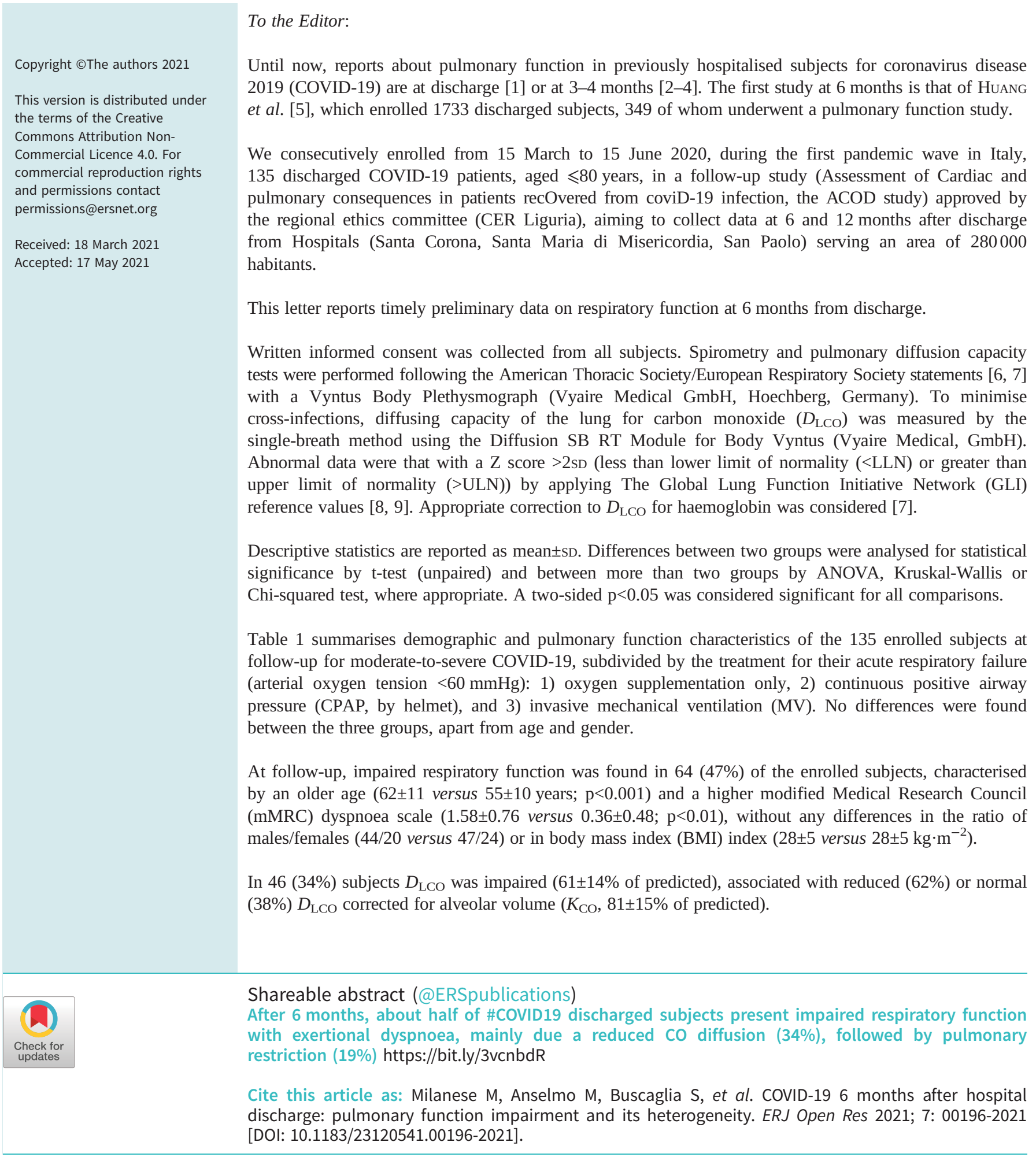


TABLE 1 Clinical characteristics and lung function by COVID-19 severity at 6 months from discharge

\begin{tabular}{|c|c|c|c|c|c|}
\hline & Whole cohort & Oxygen supplementation & CPAP & MV & $\mathrm{p}$-value \\
\hline Subjects n (\%) & 135 & $86(64)$ & $29(21)$ & $20(15)$ & \\
\hline Age, years & $59 \pm 11$ & $57 \pm 12^{\#}$ & $61 \pm 11$ & $64 \pm 7^{\#}$ & 0.01 \\
\hline Males $\%$ total & 67 & $61^{\#}$ & 70 & $85^{\#}$ & 0.04 \\
\hline $\mathrm{BMI}, \mathrm{kg} \cdot \mathrm{m}^{-2}$ & $28 \pm 5$ & $27 \pm 4$ & $29 \pm 7$ & $29 \pm 3$ & NS \\
\hline Current smokers n (\%) & $4(3)$ & $2(1.5)$ & $2(1.5)$ & 0 & NS \\
\hline Former smokers n (\%) & $25(18)$ & $19(14)$ & $5(3)$ & $1(1)$ & NS \\
\hline COPD n (\%) & $4(3)$ & 0 & $1(1.5)$ & $1(1.5)$ & NS \\
\hline Asthma n (\%) & $3(2)$ & 0 & 0 & $3(2)$ & NS \\
\hline mMRC score & $0.93 \pm 0.84$ & $0.90 \pm 0.89$ & $1.07 \pm 0.75$ & $0.85 \pm 0.75$ & NS \\
\hline mMRC score $>1$ & $27(20)$ & $16(12)$ & $7(5)$ & $4(3)$ & NS \\
\hline TLC, L & $5.72 \pm 1.28$ & $5.73 \pm 1.23$ & $5.62 \pm 1.65$ & $5.79 \pm 1.28$ & NS \\
\hline TLC, \% predicted & $96 \pm 33$ & $96 \pm 17$ & $90 \pm 18$ & $89 \pm 13$ & NS \\
\hline TLC $<$ LLN & $25(19)$ & $12(9)$ & $8(6)$ & $5(4)$ & NS \\
\hline RV, L & $2.09 \pm 0.80$ & $2.13 \pm 0.82$ & $2.01 \pm 0.77$ & $2.05 \pm 0.76$ & NS \\
\hline RV, \% predicted & $96 \pm 33$ & $100 \pm 33$ & $89 \pm 32$ & $87 \pm 30$ & NS \\
\hline $\mathrm{RV}>\mathrm{ULN}$ & $10(7)$ & $8(6)$ & $3(2)$ & $2(2)$ & NS \\
\hline $\mathrm{RV} / \mathrm{TLC}$ & $0.36 \pm 0.10$ & $0.37 \pm 0.11$ & $0.35 \pm 0.08$ & $0.35 \pm 0.09$ & NS \\
\hline $\mathrm{RV} / \mathrm{TLC}, \%$ predicted & $96 \pm 24$ & $99 \pm 27$ & $92 \pm 20$ & $91 \pm 22$ & NS \\
\hline FVC, L & $3.61 \pm 0.65$ & $3.56 \pm 0.92$ & $3.72 \pm 1.09$ & $3.71 \pm 0.72$ & NS \\
\hline FVC, $\%$ predicted & $91 \pm 16$ & $90 \pm 17$ & $94 \pm 16$ & $92 \pm 12$ & NS \\
\hline $\mathrm{FEV}_{1}, \mathrm{~L}$ & $2.92 \pm 0.96$ & $2.91 \pm 0.74$ & $2.94 \pm 0.86$ & $2.91 \pm 0.69$ & NS \\
\hline $\mathrm{FEV}_{1}, \%$ predicted & $94 \pm 16$ & $94 \pm 16$ & $94 \pm 16$ & $92 \pm 14$ & NS \\
\hline $\mathrm{FEV}_{1} / \mathrm{VC}$ & $0.81 \pm 0.07$ & $0.82 \pm 0.07$ & $0.79 \pm 0.07$ & $0.79 \pm 0.08$ & NS \\
\hline $\mathrm{FEV}_{1} / \mathrm{VC}, \%$ predicted & $101 \pm 9$ & $102 \pm 9$ & $100 \pm 9$ & $100 \pm 10$ & NS \\
\hline $\mathrm{FEV}_{1} / \mathrm{VC}<\mathrm{LLN}$ & $11(8)$ & $7(5)$ & $3(2)$ & $2(1)$ & NS \\
\hline$D_{\mathrm{LCO}}, \mathrm{mmol} \cdot \mathrm{kPa}^{-1} \cdot \mathrm{min}^{-1}$ & $7.20 \pm 2.06$ & $7.29 \pm 2.16$ & $7.02 \pm 1.87$ & $7.06 \pm 1.96$ & NS \\
\hline$D_{\mathrm{Lco}}, \%$ predicted & $82 \pm 20$ & $83 \pm 21$ & $80 \pm 16$ & $79 \pm 20$ & NS \\
\hline$D_{\text {LCO }}<$ LLN & $46(34)$ & $27(20)$ & $11(8)$ & $9(7)$ & NS \\
\hline$K_{\mathrm{CO}}, \mathrm{mmol} \cdot \mathrm{kPa}^{-1} \cdot \mathrm{min}^{-1} \cdot \mathrm{L}^{-1}$ & $1.37 \pm 0.26$ & $1.38 \pm 0.27$ & $1.36 \pm 0.27$ & $1.35 \pm 0.22$ & NS \\
\hline$K_{\mathrm{co}}, \%$ predicted & $95 \pm 18$ & $94 \pm 18$ & $96 \pm 19$ & $98 \pm 19$ & NS \\
\hline$K_{\mathrm{CO}}<\mathrm{LLN}$ & $17(13)$ & $11(8)$ & $4(3)$ & $3(2)$ & NS \\
\hline
\end{tabular}

Data are presented as mean \pm SD, unless otherwise stated. All percentages are calculated as $\%$ of total number of enrolled subjects ( $n=135)$. CPAP: continuous positive airway pressure; MV: mechanical ventilation; BMI: body mass index; mMRC: modified Medical Research Council dyspnoea scale (at 6 months); TLC: total lung capacity; LLN: lower limit of normality; RV: residual volume; ULN: upper limit of normality; FVC: forced vital capacity; $\mathrm{FEV}_{1}$ : forced expiratory volume in $1 \mathrm{~s}$; VC: vital capacity; $D_{\mathrm{Lco}}$ : diffusing capacity of the lung for carbon monoxide; $K_{\mathrm{CO}}$ : transfer coefficient of the lung for carbon monoxide ( $D_{\mathrm{LCO}}$ corrected for alveolar volume); Ns: nonsignificant. ": within each row, identical superscripts indicate significant difference.

Table 2 reports the pathophysiological classification [10] of the impairment found: pulmonary restriction (total lung capacity $<\mathrm{LLN}$ ), isolated reduction of diffusing capacity of the lung for carbon monoxide $\left(D_{\text {LCO }}<\mathrm{LLN}\right.$ ), airway obstruction (forced expiratory volume in $1 \mathrm{~s}\left(\mathrm{FEV}_{1}\right)$ /forced vital capacity (FVC) $<\mathrm{LLN}$ ), and isolated air trapping (residual volume $>\mathrm{ULN}$ ). No differences were found between groups in terms of age, male/female ratio, BMI or mMRC score. $\mathrm{K}_{\mathrm{CO}} \%$ of predicted was higher in the group with a restrictive pattern versus that with isolated $D_{\mathrm{LCO}}$ reduction $(\mathrm{p}=0.04)$.

At follow-up, $D_{\text {LCO }}$ reduction was mainly associated with pulmonary restriction (53\%), as expected, and less frequently with airway obstruction/airway trapping (8\%), but also isolated (38\%). In the latter case, subjects did not report pulmonary thromboembolism during hospitalisation or indirect signs of pulmonary hypertension at follow-up.

When comparing our data with that of HuANG et al. [5], in moderate-to-severe COVID-19 ( $\mathrm{n}=260)$, the impairment of respiratory function is similar among subjects requiring supplemental oxygen and less among those requiring CPAP or MV. Specifically, based on this subdivision, $D_{\text {LCO }}$ was impaired in 31 and $40 \%$ of subjects (versus 29 and 56\%), pulmonary restriction was present in 14 and 26\% of subjects (versus 10 and $35 \%$ ), and $\mathrm{FEV}_{1} / \mathrm{FVC}<\mathrm{LLN}$ in 8 and $10 \%$ of the subjects (versus $\mathrm{FEV}_{1} / \mathrm{FVC}<0.7$ in 8 and $2 \%$ ). It is noteworthy that HuANG et al. [5] did not use the Z score criterium, with a possible overestimation, and that the mean age of those who underwent spirometry in their study was unknown. At 8 months, using the 


\begin{tabular}{|c|c|c|c|c|c|}
\hline & TLC $<$ LLN & $D_{\text {LCo }}<$ LLN & $\mathrm{FEV}_{1} / \mathrm{FVC}<\mathrm{LLN}$ & $\mathrm{RV}>\mathrm{ULN}$ & $\mathrm{p}$-value \\
\hline Subjects n & 25 & 18 & 11 & 10 & \\
\hline$\%$ of discharged subjects & 19 & 13 & 8 & 7 & \\
\hline Age, years & $62 \pm 10$ & $59 \pm 12$ & $68 \pm 5$ & $64 \pm 6$ & NS \\
\hline Males/females $n / n$ & $20 / 5$ & $10 / 8$ & $8 / 3$ & $5 / 4$ & NS \\
\hline $\mathrm{BMI}, \mathrm{kg} \cdot \mathrm{m}^{-2}$ & $28 \pm 5$ & $27 \pm 4$ & $28 \pm 5$ & $28 \pm 4$ & NS \\
\hline Current smokers $\mathrm{n}$ & 1 & 0 & 1 & 0 & \\
\hline Former smokers $\mathrm{n}$ & 2 & 1 & 3 & 2 & \\
\hline COPD n & 0 & 0 & 4 & 0 & \\
\hline Asthma n & 0 & 0 & 1 & 0 & \\
\hline CPAP n/total & $8 / 29$ & $2 / 29$ & $3 / 29$ & $1 / 29$ & NS \\
\hline MV n/total & $6 / 20$ & $0 / 20$ & $2 / 20$ & $1 / 20$ & NS \\
\hline mMRC dyspnoea, score & $1.84 \pm 0.80$ & $1.22 \pm 0.55$ & $1.27 \pm 0.90$ & $1.3 \pm 0.67$ & NS \\
\hline TLC, L & $4.54 \pm 1.05$ & $5.36 \pm 1.04$ & $6.07 \pm 1.22$ & $6.89 \pm 1.60$ & \\
\hline TLC, \% & $69 \pm 9$ & $90 \pm 10$ & $106 \pm 13$ & $114 \pm 12$ & \\
\hline $\mathrm{RV}, \mathrm{L}$ & $1.45 \pm 0.48$ & $1.99 \pm 0.67$ & $3.28 \pm 0.86$ & $3.44 \pm 0.62$ & \\
\hline RV, \% predicted & $63 \pm 21$ & $92 \pm 22$ & $138 \pm 24$ & $155 \pm 18$ & \\
\hline $\mathrm{RV} / \mathrm{TLC}$ & $0.33 \pm 0.10^{\#, 91}$ & $0.37 \pm 0.09^{\S,+}$ & $0.52 \pm 0.09^{\#, \S}$ & $0.51 \pm 0.99^{\natural,+}$ & 0.01 \\
\hline $\mathrm{RV} / \mathrm{TLC}, \%$ predicted & $82 \pm 28^{\#, 9}$ & $96 \pm 21^{\S,+}$ & $125 \pm 21^{\#, \S}$ & $130 \pm 20^{4,+}$ & 0.01 \\
\hline FVC, L & $3.11 \pm 0.85$ & $3.36 \pm 0.71$ & $2.92 \pm 0.81$ & $3.40 \pm 1.25$ & NS \\
\hline FVC, \% predicted & $76 \pm 14 \S$ & $89 \pm 14 \S$ & $85 \pm 19$ & $90 \pm 19$ & 0.04 \\
\hline $\mathrm{FEV}_{1}, \mathrm{~L}$ & $2.69 \pm 0.67$ & $2.73 \pm 0.56$ & $1.93 \pm 0.53$ & $2.83 \pm 0.97$ & NS \\
\hline $\mathrm{FEV}_{1}, \%$ predicted & $85 \pm 13$ & $92 \pm 12$ & $72 \pm 17$ & $97 \pm 19$ & NS \\
\hline $\mathrm{FEV}_{1} / \mathrm{VC}$ & $0.85 \pm 0.04$ & $0.81 \pm 0.05$ & $0.67 \pm 0.06$ & $0.84 \pm 0.06$ & \\
\hline $\mathrm{FEV}_{1} / \mathrm{VC}, \%$ predicted & $109 \pm 6$ & $102 \pm 6$ & $83 \pm 5$ & $107 \pm 7$ & \\
\hline$D_{\mathrm{LcO}}, \mathrm{mmol} \cdot \mathrm{kPa}^{-1} \cdot \mathrm{min}^{-1}$ & $6.16 \pm 1.97$ & $5.36 \pm 1.09$ & $5.67 \pm 2.02$ & $6.95 \pm 2.19$ & NS \\
\hline$D_{\text {Lco }} \%$ predicted & $68 \pm 19$ & $63 \pm 10$ & $73 \pm 28$ & $82 \pm 17$ & NS \\
\hline$K_{\mathrm{CO}}, \mathrm{mmol} \cdot \mathrm{kPa}^{-1} \cdot \mathrm{min}^{-1} \cdot \mathrm{L}^{-1}$ & $1.34 \pm 0.26$ & $1.19 \pm 0.27$ & $1.19 \pm 0.34$ & $1.38 \pm 0.11 \S$ & NS \\
\hline$K_{\mathrm{co}}, \%$ predicted & $97 \pm 21^{\S}$ & $80 \pm 13^{\S}$ & $85 \pm 28$ & $98 \pm 10$ & 0.04 \\
\hline \multicolumn{6}{|c|}{ 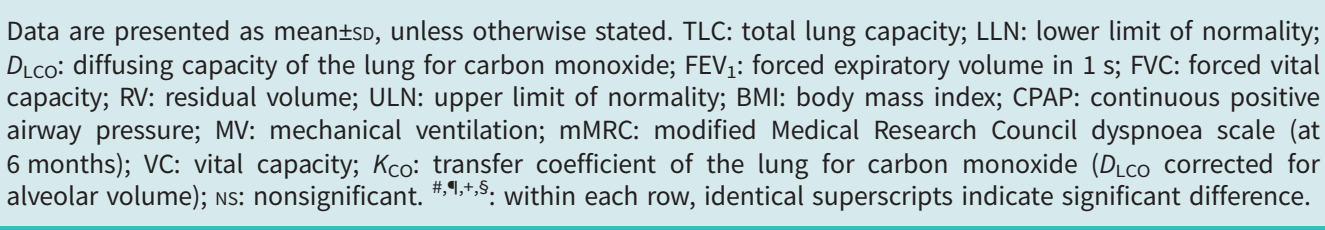 } \\
\hline
\end{tabular}

Z score criterium, BARISIONE et al. [11] found fewer subjects with impaired $D_{\text {LCO }}$ (20\%), but in mild-to-severe COVID-19 and after having carefully excluded all subjects with comorbidities (including obesity) potentially affecting $D_{\mathrm{LCO}}$.

As in the study of Mo et al. [1], which was carried out at hospital discharge, for about 29 out of 46 $D_{\mathrm{LCO}}$-impaired patients, the $\mathrm{K}_{\mathrm{CO}}$ was still within the normal range, which might indicate that the $D_{\mathrm{LCO}}$ decrease was more than the $\mathrm{K}_{\mathrm{CO}}$ decrease, or, in other words, that lung volume is contributing to the gas exchange impairment. However, the relationship between alveolar volume $\left(V_{\mathrm{A}}\right), D_{\mathrm{LCO}}$ or $\mathrm{K}_{\mathrm{CO}}$ is complex and any interpretation a surmise. By using diffusing capacity of the lung for nitric oxide $\left(D_{\text {LNO }}\right)$, BARISIONE et al. [11] suggest that a decreased alveolar membrane diffusive conductance (DM) is more frequent and persistent than the reduction of pulmonary capillary blood volume $\left(\mathrm{V}_{\mathrm{C}}\right)$ in the recovery phase, at 8 months from discharge.

Regarding the restrictive pattern, in the study of Mo et al. [1], at discharge, it was interpreted as a consequence of a critical illness (due to a transient impairment in mechanical properties of the chest wall and respiratory muscles). In our study, after 6 months, is more suggestive of a change in the elastic properties of the lung.

Airway obstruction $(n=11)$ or isolated air trapping $(n=10)$ was present in $15 \%$ of the subjects at follow-up. Even subtracting known $(n=4)$ or underdiagnosed (one current and three former smokers) COPD, a value of $9 \%$ among the discharged is still higher to the expected rate within a population of their age. Air trapping (an increase of residual volume (RV) and RV/TLC ratio) can be interpreted as an involvement of 
small airways not yet detected using conventional pulmonary function tests (i.e. FEV 1 /FVC ratio). An inflammatory process in the small airways could contribute to airway closure, by interfering with surfactant activity, by increasing the volume of intraluminal material or, more consistent in our 6 months after discharge subjects, by airway remodelling [12].

Finally, Huang et al. [5] reported data on 89 subjects not requiring supplemental oxygen (mild pneumonia). As our subjects were all affected by acute respiratory failure, we have no data to compare. However, we found that among 20 subjects undergoing spirometry for exertional dyspnoea 6 months after SARS-CoV-2 infection recovered from at home, 12 presented an impaired respiratory function. Apart from four former smokers probably affected by underdiagnosed emphysema (TLC $120 \pm 9 \%$, RV 169 $\pm 30 \%$, $D_{\text {LCO }} 74 \% \pm 2$ of predicted) and one asthmatic subject ( $\mathrm{FEV}_{1} /$ vital capacity $66 \%, \mathrm{FEV}_{1} 48 \%$ of predicted), the other seven were nonsmokers and previously healthy subjects reporting a reduced $D_{\text {LCO }}(65 \pm 9 \%$ of predicted), associated with a restrictive pattern (TLC $67 \pm 8 \%$ of predicted) in three of them. These results are in line with those reported by TRINKMANN et al. [13] on nonhospitalised subjects, but at 3 months [10] and after a first evaluation in the emergency department.

There are some limitations in our study. First, the lack of baseline pulmonary function data before COVID-19. However, patients with chronic respiratory disease were a minority, as were current or former smokers, and none of the subjects had a history of pulmonary fibrosis. Secondly, the association with computed tomography chest images were not analysed in this preliminary report.

In conclusion, our study reveals that after 6 months from discharge for moderate-to-severe COVID-19 about half of the enrolled subjects presented an impaired respiratory function and a significant exertional dyspnoea. Although it is tempting to speculate on the pathophysiology of the type of impairment found, our aim is to report timely to clinicians its entity and heterogeneity, consistent with the complex pathophysiology of COVID-19 [14]. Long-term follow-up (i.e. at 12 months) is required (ongoing) and research protocols with tools not yet routinely available $\left(D_{\mathrm{LNO}}\right)$ or for highly specialised centres (forced oscillatory technique) to be developed.

\section{Manlio Milanese ${ }^{1}$, Marco Anselmo ${ }^{1}$, Sandra Buscaglia ${ }^{1}$, Luca Garra ${ }^{2}$, Riccardo Goretti ${ }^{1}$, Lionello Parodi ${ }^{1}$, Giovanni Riccio ${ }^{3}$, Rodolfo Tassara ${ }^{1}$ and Paola Gnerre ${ }^{1}$ on behalf of the ACOD Group}

${ }^{1}$ Dipartimento Medico, ASL 2 Savonese, Savona, Italy. ${ }^{2}$ Direzione Sanitaria, ASL 2 Savonese, Savona, Italy. ${ }^{3}$ Struttura Complessa Malattie Infettive Osteoarticolari, ASL 2 Savonese, Albenga (SV), Italy.

Corresponding author: Manlio Milanese (m.milanese@asl2.liguria.it)

Acknowledgement: We thank Monica Bruzzone and Pietro Peluso (Dipartimento Medico, ASL 2 Savonese, Savona, Italy) for the management of spirometric data.

ACOD Group Collaborators: V. Bartolacci, A. Beltramo, A. Bovero, G. Carrega, G. Casalino Finocchio, P. De Leo, V. Ghiglione, S. Grignolo, M. Izzo, N.E. Malfatto, M. Marturano, D. Mela, M. Pivari, S. Tigano and A. Venosa.

Conflict of interest: None declared.

References

1 Mo X, Jian W, Su Z, et al. Abnormal pulmonary function in COVID-19 patients at time of hospital discharge. Eur Respir J 2020; 55: 2001217.

2 Lerum TV, Aaløkken TM, Brønstad E, et al. Dyspnoea, lung function and CT findings three months after hospital admission for COVID-19. Eur Respir J 2021; 57: 2003448.

3 Guler A, Ebner L, Beigelman C, et al. Pulmonary function and radiological features four months after COVID-19: first results from the national prospective observational Swiss COVID-19 lung study. Eur Respir J 2021; 57: 2003690.

4 Bellan M, Soddu D, Balbo PE, et al. Respiratory and psychophysical sequelae among patients with COVID-19 four months after hospital discharge. JAMA Netw Open 2021; 4: e2036142.

5 Huang C, Huang L, Wang Y, et al. 6-month consequences of COVID-19 in patients discharged from hospital: a cohort study. Lancet 2021; 397: 220-232. 
6 Graham BL, Steenbruggen I, Miller MR, et al. Standardization of Spirometry 2019 Update. An Official American Thoracic Society and European Respiratory Society Technical Statement. Am J Respir Crit Care Med 2019; 200: e70-e88.

7 Graham BL, Brusasco V, Burgos F, et al. 2017 ERS/ATS standards for single-breath carbon monoxide uptake in the lung. Eur Respir J 2017; 49: 1600016.

8 Quanjer PH, Stanojevic S, Cole TJ, et al. Multi-ethnic reference values for spirometry for the 3-95-yr age range: the global lung function 2012 equations. Eur J Respir 2012; 40: 1324-1343.

9 Stanojevic S, Graham BL, Cooper BG, et al. Official ERS technical standards: Global Lung Function Initiative reference values for the carbon monoxide transfer factor for Caucasians. Eur Respir J 2017; 50: 1700010.

10 Pellegrino R, Brusasco V, Viegi G, et al. Interpretative strategies for lung function tests. Eur Respir J 2005; 26: 948-968.

11 Barisione G, Brusasco V. Lung diffusing capacity for nitric oxide and carbon monoxide following mild-to-severe COVID-19. Physiol Rep 2021; 9: e14748.

12 Ryu JH, Myers JL, Swensen SJ. Bronchiolar disorders. Am J Respir Crit Care Med 2003; 168: 1277-1292.

13 Trinkmann F, Müller M, Reif A, et al. Residual symptoms and lower lung function in patients recovering from SARS-CoV-2 infection. Eur Respir J 2021; 57: 2003002.

14 Ackermann M, Vereleden SE, Kuehnel $\mathrm{M}$, et al. Pulmonary vascular endothelialitis, thrombosis and angiogenesis in COVID-19. N Engl J Med 2020; 383: 120-128. 